\title{
A Qualitative Framework for Evaluating Participation on the Geoweb
}

\section{Blake Byron Walker}

Ryerson University

\section{Claus Rinner}

Ryerson University

Walker, B. B., \& Rinner, C. (2013). A qualitative framework for evaluating participation on the Geoweb. URISA Journal, 25(2), 15-24.

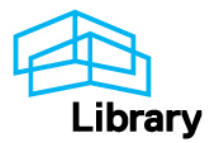




\section{Journal \\ Vol. 25 No. 2 2013 of the Urban and Regional Information Systems Association}
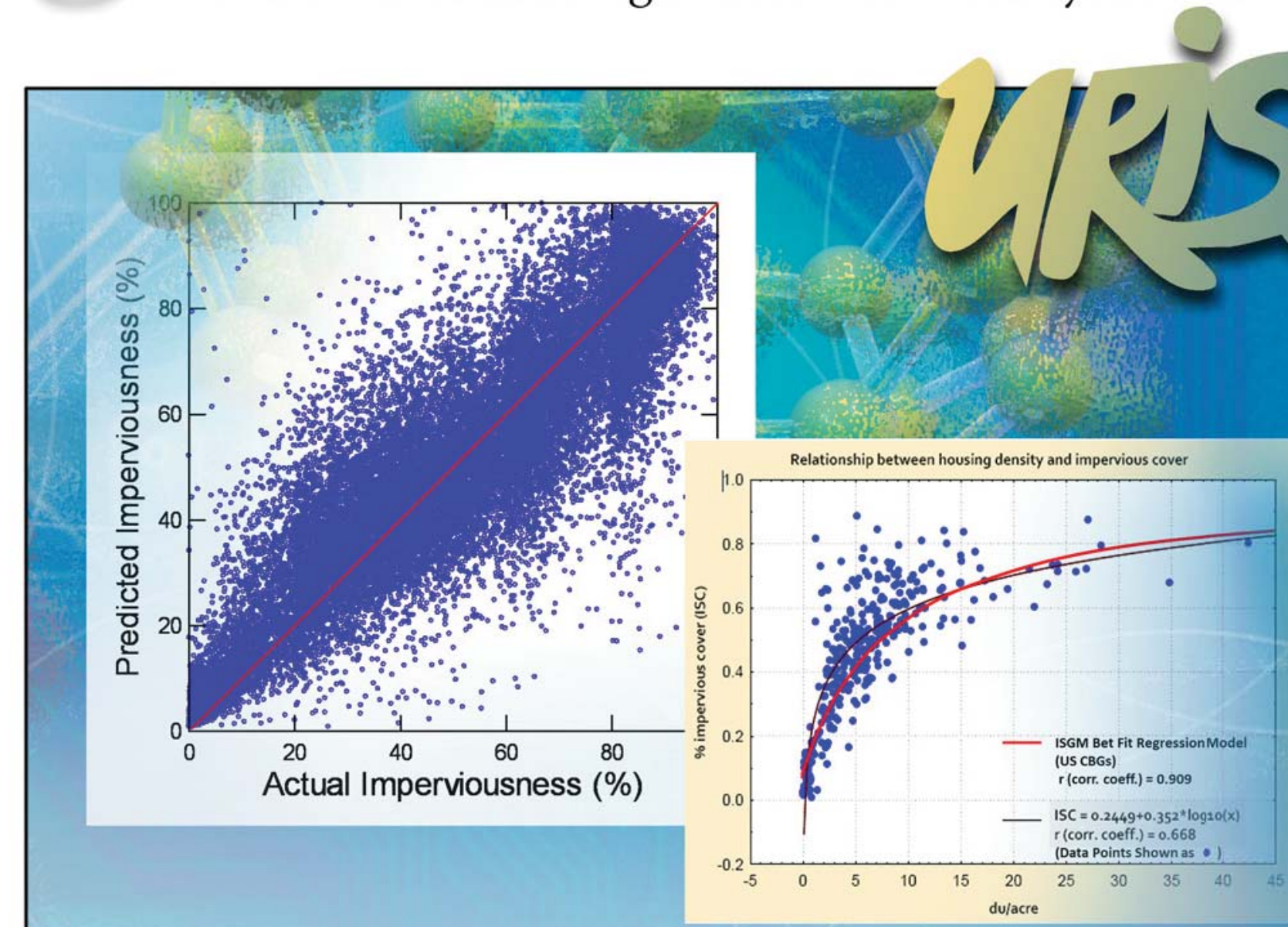

Smart Eco-path Finder for Mobile GIS Users

A Qualitative Framework for Evaluating Participation on the Geoweb

A Place-based Tool for Assessing Cumulative Impervious Surface Outcomes of Proposed Development Scenarios

The Role of Collaboration in Spatial Data Infrastructures

Papers of Practice, Technical Reports and Industry Notes

Building the School Attendance Boundary Information System (SABINS):

Collecting, Processing, and Modeling K to I2 Educational Geography

Improving Cadastre: Development of a Workflow Prototype Utilizing ESRI's Parcel Fabric 
Volume $25 \cdot$ No. $2 \cdot 2013$

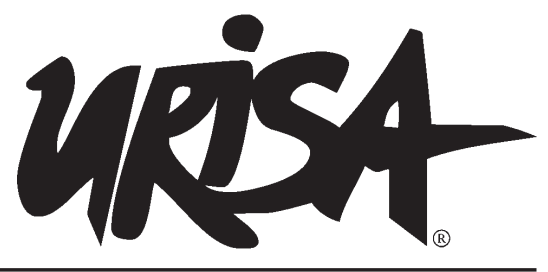

Journal of the Urban and Regional Information Systems Association CONTENTS

5 Smart Eco-path Finder for Mobile GIS Users Ko Ko Lwin and Yuji Murayama

15 A Qualitative Framework for Evaluating Participation on the Geoweb Blake Byron Walker and Claus Rinner

25 A Place-based Tool for Assessing Cumulative Impervious Surface Outcomes of Proposed Development Scenarios Kevin Ramsey and Aaron Poresky

39 The Role of Collaboration in Spatial Data Infrastructures Watse T. Castelein, Arnold K. Bregt, and Lukasz Grus

Papers of Practice, Technical Reports and Industry Notes

49 Building the School Attendance Boundary Information System (SABINS): Collecting, Processing, and Modeling K to 12 Educational Geography Salvatore Saporito, David Van Riper, and Ashwini Wakchaure

63 Improving Cadastre: Development of a Workflow Prototype Utilizing ESRI's Parcel Fabric

Linda M. Foster and Justine I. Blanford 


\title{
A Qualitative Framework for Evaluating Participation on the Geoweb
}

\author{
Blake Byron Walker and Claus Rinner
}

\begin{abstract}
The participatory Geoweb emerges from the synthesis of map-based online applications and Web 2.0 concepts such as user-generated content, enhanced interactivity, and cloud computing. The result is a wide range of tools and projects using these tools to communicate, collaborate, deliberate, and inform spatial decision making. This article draws upon the literature in participatory geographic information systems to propose the "3E Framework," which provides both a structured conceptual model and a practical tool for the evaluation of projects on the participatory Geoweb. The framework deconstructs participation on the Geoweb into the provider and public realms and represents the engagement, empowerment, and enactment processes. It includes 20 evaluation questions that are derived from themes in the literature.
\end{abstract}

\section{INTRODUCTION}

The Geospatial Web (Geoweb) includes a variety of interactive online mapping applications to which users can contribute contents (Scharl and Tochtermann 2007). While researchers have yet to settle on a single definition of the Geoweb, Crampton (2009) provides several common denominators of this "explosion of new spatial media on the web": cartography, citizen-orientation, and strong ties to the notion of public production of knowledge in participatory contexts ("crowdsourcing," p. 91). The term participatory Geoweb was coined by Sieber (2008) to describe "the involvement of advocacy nonprofits and marginalized communities ... in the geospatial technologies of Web 2.0" (p. 59). Geoweb tools can function as powerful conduits for gathering volunteered geographic information (VGI) for collaborative planning, deliberation, and argumentation (Flaxman 2010, Goodchild 2010).

Each Geoweb application has its own objectives, target users, types of contributions, spatial contexts, and other attributes, resulting in substantial difficulties when trying to establish metrics for success and effectiveness. To address this challenge, this article builds on established findings in the geographic information science literature to propose a novel framework, which is designed to evaluate participatory initiatives that utilize Geoweb technologies, and may be extensible to public participation geographic information systems (PPGIS) and other participatory media. It also provides a structured approach for contextualizing the processes inherent in user participation through these media.

The following section provides the research context, background on participation, and spatial decision making, and introduces concepts used in the proposed framework. This lays the groundwork for the subsequently presented description of the "3E Framework" with its provider and public realms, interaction space, and engagement, empowerment, and enactment processes. To conclude, we describe how this framework may be deployed, outline some of its limitations, and make a call for continued efforts to unite participatory Geoweb theories with practice.

\section{RESEARCH CONTEXT}

\section{Origins of the Geoweb}

Recent years have seen the emergence of Web 2.0 as the next generation of online networking, where users contribute content by uploading files, writing reviews, rating contents, and otherwise contributing to a "collective intelligence" (Lévy 1997, GordonMurname 2006). While O'Reilly (2005) is credited with coining the term Web 2.0, it first appears six years earlier in an article by DiNucci (1999). Controversy aside, the fact remains that the Web is shifting from a static information source to an interactive platform integrating user contributions, and efforts to leverage these capabilities to empower citizens in spatial decision-making processes abound (e.g., Ward, Gibson et al. 2003; Miller 2006; Tulloch 2007; Mericskay and Roche 2010).

As the Web continues to evolve from a one-way information conduit to a multidirectional interactive space, so, too, does it adopt new spatial contexts. The concepts underpinning the Geoweb can be traced back to Herring (1994), whose U.S. Department of Defense paper postulated the implementation of "spatial indexing geometry" for battlefield mapping and simulation. He called this the beginning of the "spatialization of the internet" (p. 1). During the following decade, interactive mapping applications exploded across the Web, backed by information technology giants Google, Microsoft, and Yahoo (Goodchild 2005 Craglia, Goodchild et al. 2008). It did not take long for users worldwide to recognize the value of interactive "cybercartography"; Peterson's (2005) study concluded that maps were, at the time, the second most frequent request over the Internet (next to weather forecasts) (Taylor and Claquard 2006).

The synthesis of Web 2.0 concepts with online mapping technologies produces the participatory Geoweb, a "phenomenon that has taken the world of geographic information by storm" (Goodchild 2007, Maguire 2007, Tulloch 2007). In the same 
fashion that Web 2.0 encourages crowdsourcing (the accumulation of data submitted by many users, e.g., Wikipedia), Goodchild (2007, 2008) brought attention to the notion of volunteered geographic information (VGI), describing user-generated, spatially referenced information (e.g., Wikimapia). In this work, Goodchild conceptualizes "citizens as sensors" for the gathering of intelligence directly from sources in the field. In recent years, the concept of the produser has been developed to describe a user of Web 2.0 technologies who both accesses and contributes information (Budhathoki et al. 2008, Coleman et al. 2009).

However, this raises concerns among other researchers, who identify abundant questions and concerns with the quality and veracity of VGI. Research in PPGIS had been active before the concept of VGI was formally established, and a body of literature tying theory with the exponentially growing use of geographic tools in participatory decision making continues to mature (Pickles 1997; Kingston, Carver et al. 2000; Jankowski and Nyerges 2001; Breitbart 2003; McCall 2003; Sieber 2006; Pain and Kindon 2007).

\section{PERSPECTIVES ON PPGIS}

Many participatory Geoweb applications can be conceptualized in PPGIS terms, for they are tools for implementing spatial information and gathering input from the public. It is thus advantageous to draw upon the substantial literature examining the use of PPGIS to engage stakeholders, gather information, and inform decision makers. This body of research ranges from applied studies of PPGIS in real-world projects (Han and Peng 2003) to theoretical explorations of these technologies from a variety of perspectives (Bussi 2001, Ghose 2001, Kwan 2002, Sieber 2006). Such previous efforts to conceptually synthesize GIS and public participation provide fundamental building blocks for the framework proposed here.

The features by which the participatory Geoweb is most commonly distinguished from PPGIS are scale (of both number of participants and volume of data), integration of increasingly ubiquitous mobile and social networking technologies, decreasing levels of analytical capability, and less required technological expertise for use (Cinnamon and Schuurman 2010, Crampton et al. 2013).

Peng $(1999,2001)$ provides frameworks for the planning of Internet-based GIS systems from an IT perspective, and also proposes a taxonomy for Web-based public participation systems, based on their functions and contents. While this matrix-based classification system provides a straightforward typology for characterizing Web-based participation tools, it does not delve into the abstract social and political processes underlying participation. Carver et al. (2001) discuss their findings from two PPGIS case studies and forecast the expansion of Internet-based public participation. Many of the issues they raise continue to influence participation on the Geoweb, namely access to the Internet, IT knowledge, and political factors affecting the implementation of publicly generated information, concerns that are further explored by McCall (2003). To address these aspects, Jankowski and $\mathrm{Ny-}$ erges (2003) propose the EAST 2 framework for examining the interaction of sociopolitical constructs and influences that occur with the use of participatory GIS. Dragicevic and Balram (2004) provide a framework for conducting Web-based, collaborative spatial deliberation in collaborative resource management, with a focus on equity and access. Sieber (2006) identifies four broad social themes found throughout the PPGIS literature, examines specific elements of these themes and their interactions, and proposes a framework for academic evaluation of PPGIS along these lines. A common theme throughout the PPGIS literature is the effort to reconcile and position GIS concepts within the broader participation literature, generally drawn in sociopolitical motifs.

\section{SOCIOPOLITICAL DIMENSIONS OF PARTICIPATION}

Participation in the decision-making context does not settle on a singular definition, although many authors do point to its roots in democratic theory and empowerment of the public (Rosenstone and Hansen 1993; Perkins, Brown et al. 1996; Bussi 2001; Beierle and Cayford 2002; Abelson, Forest et al. 2003; Nyerges 2005; Miller 2006). Wang and French (2008) divide the ingredients of e-participation into methodology, community, and technology, and proceed to dissect "common understanding" into actionable elements of an "e-democracy"; Nyerges (2005) contrasts "deliberative" and "representative" democracies, highlighting the former as relevant to participatory decision making, while the latter better describes elected representation. Schlossburg and Shuford (2005) divide participation into two base concepts: the acts of participation themselves and the broad goals of participation. The prevailing view of the latter has been that of a catalyst for the shift of power from traditional hierarchical structures to the grassroots, originating from Arnstein (1969). She defined participation as "the redistribution of power that enables the have-not citizens, presently excluded from the political and economic processes, to be deliberately included in the future" (p. 351). Arnstein's "ladder of participation" exemplifies this dynamic along a scale from "manipulation" to "citizen control." Conversely, Wiedemann and Femers (1993) model public participation from a government perspective, characterizing levels of participation by their involvement in a decision-making process. It is, however, necessary to heed the differentiation between the roles of the leaders and the public, as Connor (2007) explains, taking the view that participation is a tool for the prevention and mitigation of conflict between these two bodies.

\section{ACTS OF PARTICIPATION}

The instantiations of participation in spatial decision making vary widely, PPGIS being the dominant medium established in the literature. However, PPGIS represent only one genus of a rapidly evolving mass of geographic tools for public use. The focus of this work is the participatory Geoweb species specifically tasked with collecting public knowledge to inform spatial decision making.

The acts of participation are examined by Nyerges (2005), 
who identifies four independent types of participatory actions: data operation, analysis, speech/dialogue, and deliberation, while Rinner et al. (2011) discuss the "analytic-deliberative" perspective of decision making, identifying information processing and dialogue as respectively subordinate stages to analysis and deliberation.

The participation acts and overarching goals can be reconciled by implementing Jankowski and Nyerges' (2001) “macro-micro approach" to structuring decision situations. This system divides each macro phase (intelligence, design, and choice) into four microactivities (gathering, organization, selection, and review), simplifying the analytic-deliberative decision-making process. Their EAST2 framework is used to interpret the macrophases, and is accompanied by eight constructs in decision-making situations that seek to explain the different perspectives involved. Future investigation of the acts of participation need not be limited to a geographical realm, for example, Brandt (2006) investigates exploratory design games as potential participation frameworks.

While previous research has been successful in theoretically and empirically examining the social, political, and material dimensions of public participation in spatial decision making, no distinct method for implementing these findings into the planning or evaluation phases of a project is yet found in the literature. To address this gap, we propose a novel framework accompanied with specific questions for evaluating projects on the participatory Geoweb.

\section{THE 3E FRAMEWORK}

The 3E Framework links theory and practice by using the aforementioned dimensions of participation and the Geoweb to guide the post hoc evaluation of projects that use the participatory Geoweb to inform spatial decision making. As illustrated in Figure 1 , this framework deconstructs participation into a three-stage process (engagement, empowerment, enactment) occurring across three conceptual spaces (provider realm, public realm, Geoweb interaction space). Twenty qualitative questions pertaining to these spaces and processes are designed as guideposts to assist with the evaluation of a project on the participatory Geoweb. In this section, we define the framework elements and present the accompanying questions.

\section{KEY CONCEPTS}

Many authors point to engagement as central to democracy (Owens 2000, Williams 2004, Rinner and Bird 2009, Boulton 2010). Engagement in this framework encompasses both the act of securing a space in which project entities interact with participants ("publics"), and the actors and networks within that space itself (Bachimont 2000, Rowe and Frewer 2000, Gagnon and Fortin 2002, Ghose 2007). From the results of a Canada-wide survey, Robinson and Gore (2005) identify lack of public engagement as the primary limiting factor in the development of municipal policies regarding climate change. To better reach out to people, "the public" must be defined and identified. Schlossburg and
Shuford (2005) propose three definitions of who constitutes "public" in public participation: "those affected by a decision or programme"; "those who can bring important knowledge or information to a decision or programme"; and "those who have power to influence and/or affect implementation of a decision or programme" (p. 18). The publics are increasingly seen as "produsers" of VGI (Budhathoki et al. 2008, Coleman et al. 2009). But this conceptualization of publics in the participatory context relies on notions of representation and expertise, which can be difficult to evaluate (Rowe and Frewer 2000, Barnes, Newman et al. 2003). Furthermore, map literacy and access (digital inequalities) are significant factors in public engagement (Crampton 2009, Haklay 2013). Creighton (1983) describes five criteria for characterizing publics in participation processes: proximity to the space in question; economic stakes; utilization of the space in question; social stakes; and value systems. These are used to plan and evaluate the public realm and the engagement phase of the 3E Framework, as described below.

The empowerment phase in this framework is predicated on the view that participation is a means to politically promote citizen interests and flatten hierarchies (Arnstein 1969; Craig, Harris et al. 2002; McCall 2003). While Haklay (2013) argues that the Geoweb and other technological means of participation serve an elite body of users, resulting in a frequent overstatement of the Geoweb's ability to depoliticize decision making, others argue that the Web has the potential to empower publics more than ever by providing nearly infinite information at one's fingertips (Sieber 2006, Tulloch 2007). The proposed 3E Framework directs project planners and/or evaluators to examine power dynamics, hierarchies, and social structures inherent in participation, predicated by Ghose's (2007) assertion that the context of a specific participatory project space embodies hierarchies while providing opportunities for participants to transcend traditional power networks. This includes consideration of the "information needs" of publics to participate in a meaningful way (Jankowski, Nyerges et al. 2006). Also addressed here is Nyerges' (2005) assertion that "access to voice" is the critical basis on which participation occurs. Perkins and Brown (1996) utilize an ecological framework to predict public participation in community groups. Their physical, economic, and social indicators are reflected in the empowerment phase in the 3E Framework.

Enactment as the third process in the framework refers to the implementation of the results from participation into a decisionmaking process. While some authors argue that participation itself can be more significant than its formal outcomes (e.g., in fostering community spirit), the ultimate goal of participation is to include publics in the decision-making process (Arnstein 1969, Schlossburg and Shuford 2005, Miller 2006, Rambaldi 2006). The enactment phase examines the ways in which input gathered through participation is considered in the decisionmaking process. However, this is not always straightforward. For example, McCall (2003) identifies implementation issues with indigenous spatial knowledge. Boulton (2010) summarizes the concern that users must see results if they are to continue to 


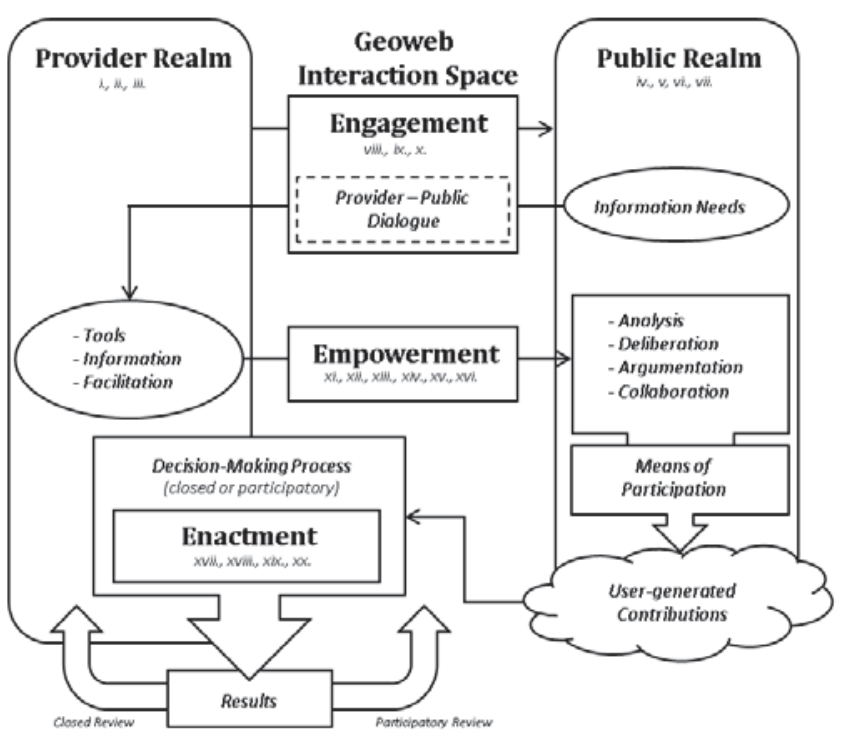

Figure 1. The 3E Framework consisting of provider and public realms, interaction space, and engagement, empowerment, and enactment processes

embrace the participatory Geoweb, and Bussi (2001) argues that there exists a fundamental gap between geography and democracy, offering six hypotheses for its cause. He points toward local and small-scale development as the first steps toward a reconciliation of the two. Elwood (2006) discusses gaps in knowledge production and subsequent implementation in decision making, a problem that the 3E Framework does not propose to overcome; however, project planners/evaluators using the framework are directed to specifically consider this phase.

To deploy this framework for the evaluation of a project on the participatory Geoweb, we provide 20 questions pertaining to various components of the framework (numbered in Figure 2). These are designed to assist the evaluator in teasing out the various dimensions of participation on the Geoweb as they apply to the project being considered.

\section{THE PROVIDER REALM}

The provider realm encompasses the project administrator's arena of operations, including project design, tool development, and (often) decision making. Three questions are used to evaluate the provider realm:

\section{i. Who is the project provider?}

Although Geoweb projects may not always follow a clear provider-user dichotomy, we argue that a provider, facilitator, or initiator must exist for a project to emerge. For example, Twitter as a generic platform can act as facilitator for a set of related tweets. If a Twitter user, or group of users, start employing a new hashtag and encourage others to join a discussion under this hashtag, they can be considered initiators of a project. Finally, if an organization invites comments via Twitter under a given hashtag on a given

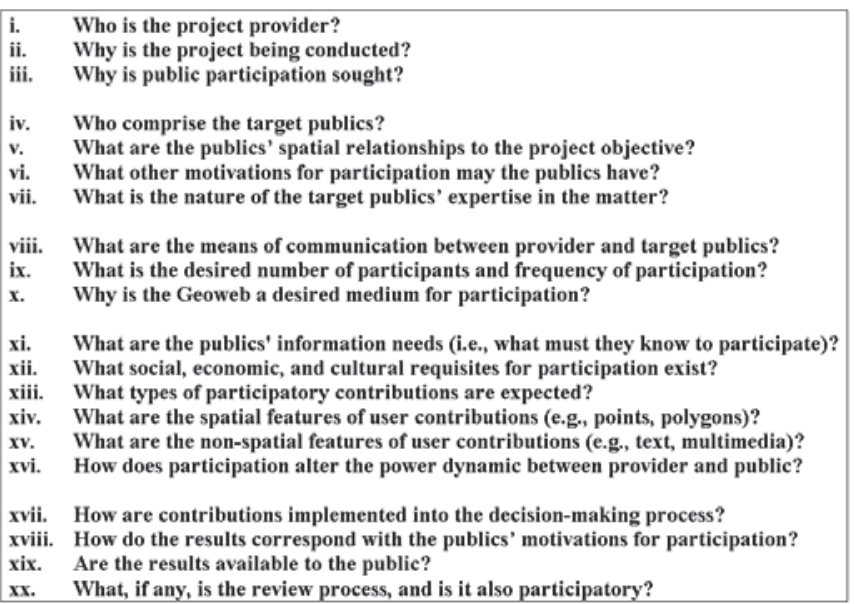

Figure 2. Evaluation questions derived from the $3 \mathrm{E}$ Framework

topic, we also would consider them under the provider realm although they would not provide the project infrastructure. Therefore, this first evaluation question asks to explicitly identify who is involved in the provider realm, a necessary step to later analyze the power dynamics between provider and public. In this case, "who" refers to the people or organizations initiating, facilitating, or administrating the project. Often, the distinction between providers and the public may be blurred. Particular attention should be paid to the actors' authority and expertise.

ii. Why is the project being conducted?

The overarching project goals are stated, including design objectives and specific delineation of the space in question. Identifying the wider project goals and scope is useful for analyzing the methods of engagement and participation, and determining if these conjugate.

iii. Why is public participation sought?

Recognizing that public participation is only one means of gathering information and opinions to inform spatial decision making, it is important to make clear the reasons why public input was required or desired. What knowledge or power is held by the public that makes their participation valuable?

\section{PUBLIC REALM}

The public realm is the conceptual space where participants analyze, deliberate, and collaborate to produce participatory contributions. Participatory contributions include input in the form of comments, data submissions, and media uploading, and is also known as "user-generated content" or VGI in geospatial applications. In this context, "public" refers to any target user group, not exclusively a civilian body of the citizenry (Rowe and Frewer 2000). 
iv. Who comprise the target publics?

Target publics can include individuals, community groups, or highly structured organizations. The physical and social settings in which participants are situated could have a significant impact on their contributions, including demographic characteristics (Cinderby 2010).

v. What are the publics' spatial relationships to the project objective?

Vital to assessing the contributions of a public is an understanding of the public's use of the space in question. This includes tangible and symbolic uses. The place of residence and, to a lesser degree, work are key components.

vi. What other motivations for participation may the publics have?

Participants may be influenced by affiliations, preferences, beliefs, and other motivators, affecting the content and quality of their participatory contributions (Coleman et al. 2009). Creighton's (1983) five criteria for evaluating publics provide a guide for identifying such influences: proximity to the space in question; economic stakes; utilization of the space in question; social stakes; and value systems. Using these criteria, we can attempt to estimate the nature and strength of such influences on the content of contributions. For example, a project to collect spatially referenced citizen input on an urban development is likely to gather polarized opinions; recognizing the motivations of the participating publics will allow evaluators to determine whether the participatory design encourages bias or division of opinion.

vii. What is the nature of the target publics' expertise in the matter?

This question draws attention to what the participants know and how their input is assessed for credibility. By examining the knowledge gap between provider and public, the project evaluator can determine if the participants are, in fact, the right group to consult.

\section{ENGAGEMENT}

The first phase of participation involves selecting and contacting the target users (publics). The conceptual space between provider and public realms in the $3 \mathrm{E}$ Framework is termed the "interaction space," through which engagement occurs. While serving as the connecting medium between the two realms, this element also represents other dynamics between the provider and publics. To determine how the relation between these two entities affects participation and the project as a whole, the question is posed:

viii. What are the means of communication between provider and target publics?

The methods by which publics are recruited into the participation process are critical to engaging the targeted group. For example, while mobile services are an excellent way to contact youth, this may not be the best method to get contributions from seniors, an instance where inperson facilitation may prove more effective. This question reflects the simple requirement that a participatory project on the Geoweb can be effective only if the target publics are reached. Furthermore, the methods of communication should facilitate a two-way dialogue in keeping with Wang and French's (2008) "community" criterion for e-democracy.

ix. What is the desired number of participants and frequency of participation?

While Geoweb technologies are able to efficiently handle larger numbers of participants and contributions relative to traditional methods, an approximation of the number of expected contributions ensures that handling the received data is within the capabilities of the project provider. While some projects only require one-time contributions, others rely on sustained participation over time and throughout the entire spatial decision-making process. If sustained participation is desired, whether or not this is achieved can help to identify areas for improving engagement.

$x$. Why is the Geoweb a desired medium for participation? This question directs evaluators to consider why other media were not deployed in place of interactive Web mapping. Themes here may include the spatial nature of the knowledge being sought, the Web presence of the target publics, and any barriers posed by other options (e.g., focus groups, telephone surveys). Findings here may reveal effective alternatives or complementary approaches to the Geoweb component of a project.

\section{EMPOWERMENT}

The second phase of participation, empowerment, addresses to participants' information needs, computer literacy, knowledge, and stakeholder status (with respect to sociopolitical dynamics) (Nyerges 2005; Jankowski, Nyerges et al. 2006; Ramsey and Wilson 2006). The following evaluation questions are designed to examine several key facets of empowerment in the participatory Geoweb context.

xi. What are the publics' information needs (i.e., what must they know to participate)?

Often, the core purpose of leveraging participatory technologies on the Geoweb is to collect VGI (Sieber 2006, Goodchild 2008). To effectively participate, the target users must have both the knowledge to contribute and the means of contributing that knowledge. This includes the ability to operate a participatory tool, analyze information, and, in some cases, deliberate, argue, and/or collaborate. This also could include knowledge about design practice, code, and economic factors. Furthermore, reciprocal learning should be considered, where users learn about the geographical, social, and political contexts through the process of participation, as observed by Elwood (2009).

xii. What social, economic, and cultural requisites for participation exist?

This question addresses issues such as Internet access, computer literacy, and language abilities. It is important to 
assess who is included, but also who is excluded by a project design, to assess its effectiveness and alternative modes of action. More comprehensive guidelines for evaluating these dimensions are found in Sieber (2006) and Haklay (2013).

xiii. What types of participatory contributions are expected? When considering the spatial information project providers seek, it is necessary to differentiate between observations, opinion, and contributed designs. The method of participation is critical in receiving participatory contributions of the desired type (Rinner et al. 2011). This influences the format of contributions, assessment of their validity, and how they are utilized in a decisionmaking regimen. This evaluation question also asks about the possibility of dialogue between participants, e.g., in a threaded discussion forum or map-based deliberation platform (Rinner et al. 2008).

xiv. What are the spatial features of user contributions (e.g., points, polygons)?

For example, users may create points to which they attach comments. Is the spatial representation appropriate for the phenomena being considered? Perhaps alternative spatial representations would prove more appropriate (e.g., a rasterbased 'paintbrush' tool to allow participants to depict land cover or a Google SketchUp-based plug-in).

xv. What are the non-spatial features of user contributions (e.g., text, multimedia)?

This question focuses more specifically on the thematic content of participant contributions. Examples here include stories/narratives, photographs, measurements, or polls/ surveys. Often the knowledge or opinion sought from participants can be enriched with other material. This question directs the evaluator to consider whether the form of contributions was suitable for effectively gathering the desired information.

xvi. How does participation alter the power dynamic between provider and public?

This question draws on responses from the engagement phase, encouraging evaluators to critically examine how the provider and public interrelate, with respect to authority and common goals. Power structures and the desire for conflict or cooperation can alter participatory contributions, and an understanding of this dynamic is necessary to evaluate the participatory project as a whole. Drawing from the perspectives in the literature that participation is a fundamentally democratic method, it is necessary to consider the ramifications of the project being analyzed in these terms. Does participation have the propensity to alter power structures? While the answer remains highly subjective and relies on how contributions are utilized, it can help to identify methodological weakness in the project design. It also must be considered that the overarching political context of a case study is vital to its interpretation (Arnstein 1969, Bussi 2001). Often, a project's effect on power dynamics is determined by how the participatory contributions are incorporated in a decision-making process, and so this step is considered independently in the following section.

\section{ENACTMENT}

This construct poses questions about the ways in which user input gathered through the participatory Geoweb is utilized in the actual decision-making process on the provider side.

xvii. How are contributions implemented into the decisionmaking process?

Considering how participatory contributions are utilized in decision making is useful in determining whether the method of participation and format of input is appropriate. The project administrators may directly handle contributions, or they may be processed and passed on to a decision-making body.

xviii.How do the results correspond with the publics' motivations for participation?

Reflecting back on questions $\mathrm{v}$ and vi, this question directs the project evaluator to examine the differences between the project outcomes and the participants' motivations for involvement. This is important for determining whether public participation effectively influenced project outcomes and provides insight into the publics' sense of engagement with the decision-making process (Elwood 2009).

xix. Are the results available to the public?

This question refers to the transparency of the decisionmaking process, whether the participants are aware of how their contributions were used and to what ends. Informing participating publics of the role their contributions make in a project may prove useful for sustained engagement and a sense of empowerment, along with an opportunity for critical reflection on their collaborative role in spatial decision making (Elwood 2009).

xx. What, if any, is the review process, and is it also participatory?

While the 3E Framework itself can be used for postproject review, this question seeks to identify any other review measures taken and whether or not project contributors also participate in the review. Perhaps those who contributed are able to suggest improvements to the Geoweb tools and procedures, or propose novel ideas for gathering, processing, and implementing contributions.

\section{DISCUSSION AND CONCLUSION}

In the post hoc evaluation of a participatory Geoweb project, the 3E Framework can be deployed to structure the project review. The evaluation questions are mapped to specific elements of the framework, and exploring each of these will assist project evaluators in relating literature-derived features of effective participation to actual project results. This work represents a step toward reconciling PPGIS theory with practical applications of the Geoweb, but also may have value in conceptualizing, framing, 
and evaluating other participatory and VGI initiatives.

The 3E Framework also may assist in the planning of future projects on the participatory Geoweb. For this purpose, the evaluation questions would be answered with intended or expected project characteristics. Discrepancies between these and factual information about the provider or public realm, and the engagement, empowerment, or enactment processes being planned, could trigger adjustments to the project prior to, and in the process of, its deployment.

Several aspects of the framework require additional study. For one, the nature of this approach suggests an opportunity for participatory review, a crucial stage often overlooked in the literature. The framework questions may represent a bias toward the provider, as participating publics may not be aware of a project's goals and means of enactment, and may have conflicting views on associated power dynamics. As such, collaboration with the target publics during the review process is encouraged. While the division of a participatory project into three conceptual spaces is convenient, the spaces remain strongly connected along many lines, and the framework may oversimplify large-scale participatory projects and complex methods of participation. As such, context-specific questions could provide additional insight into the realms, actors, and processes behind a participatory initiative.

Scalability of Geoweb projects is of significant concern and should be addressed in future research. Some authors point to localized, small-scale participation as more fundamentally democratic (Arnstein 1969, Bussi 2001), while others highlight technical approaches to address scalability (Sani and Rinner 2011). To implement more quantitative means of project evaluation, a scoring system could be devised with the addition of ordinal "provider satisfaction" and "public satisfaction" columns to the questions matrix. The responses and the perceived strengths of each project element then would be rated by all participants and standardized to produce a score. In this way, the effectiveness of a project across the framework could be rated and compared to other such projects, lending an additional dimension to the analysis.

As the Geoweb continues to grow, so, too, does the body of questions surrounding its applications to participatory design, planning, and policy making. On the one hand, the increasing complexity and sophistication of information technology may create problems for understanding Geoweb tools and their contexts. On the other hand, Geoweb tools are becoming increasingly streamlined and easy to use, thus potentially hiding the complexity of decision problems presented through them. This research offers a deconstructive method for analyzing the processes on the participatory Geoweb to better address questions surrounding its ability to democratize societal decision making, and may be extensible to PPGIS and other participatory media. An understanding of the positives and negatives of utilizing Web technologies to foster and implement public input in decisions traditionally held within rigid power structures and hierarchies benefits our transitioning views of democracy in the 21 st century, as the Web 2.0 continues to expand its influence on the people and processes that design our spaces.

\section{Acknowledgments}

Extensive comments received from Peter A. Johnson and several anonymous reviewers on previous versions of this paper are gratefully acknowledged. This research was partially supported by the GEOIDE Network of Centres of Excellence through Project PIV-41 "The Participatory Geoweb for Engaging the Public on Global Environmental Change."

\section{About the Authors}

Blake Byron Walker is a Ph.D. student in the department of geography at Simon Fraser University (SFU), Vancouver, Canada, specializing in spatial epidemiology and GIS for health informatics. Walker completed the present research as a student in the BA in Geographic Analysis program at Ryerson University. His Master's research at SFU examined geographical patterns of violent trauma, pedestrian injury, and graffiti, while his doctoral research focuses on the spatial-temporal trends in head and neck cancers in British Columbia.

Department of Geography

Simon Fraser University

8888 University Drive

Burnaby, British Columbia V5A 1 S6

Canada

Phone: (778) 782-4987

E-mail: bwalker@sfu.ca

Claus Rinner is an associate professor in the department of geography at Ryerson University, Toronto, Canada. Rinner holds degrees in applied systems sciences, applied mathematics and social sciences, and geography from the Universities of Montpellier, France, and Osnabrück and Bonn, Germany. Within geographic information science, his research contributes to enhance the mapping and analysis functions in GIS to support visual thinking and to facilitate effective and sustainable spatial decision making.

Department of Geography

Ryerson University

350 Victoria Street

Toronto, Ontario M5B 2K3

Canada

Phone: (416) 979-5000, x2686

E-mail: crinner@ryerson.ca 


\section{References}

Abelson, J., P. G. Forest, J. Eyles, P. Smith, E. Martin, and F. P. Gauvin. 2003. Deliberations about deliberative methods: Issues in the design and evaluation of public participation processes. Social Science and Medicine 57(2): 239-51.

Arnstein, S. 1969. A ladder of citizen participation. Journal of the American Institute of Planners 35(4): 216-24.

Bachimont, B. 2000. Engagement sémantique et engagement ontologique: Conception et realisation d'ontologies en Ingénierie des connaissances. In Charlet, J., M. Zacklad, G. Kassel, and D. Bourigault, Eds., Ingénierie des connaissances, évolutions récentes et nouveaux défis. Paris: Eyrolles.

Barnes, M., J. Newman, A. Knops, and H. Sullivan. 2003. Constituting the "public" in public participation. Public Administration 82(1): 379-99.

Beierle, T. C., and J. Cayford. 2002. Democracy in practice: Public participation in environmental decisions. Washington, DC: Resources for the Future.

Boulton, A. 2010. Just maps: Google's democratic map-making community? Cartographica, 45(1): 1-4.

Brandt, E. 2006. Designing exploratory design games: A framework for participation in participatory design? Proceedings of the 9th Participatory Design Conference, August 1 to 5, 2006, Trento, Italy.

Breitbart, M. M. 2003. Participatory research. In Clifford. N., and G. Valentine, Eds., Key methods in geography. London: Sage.

Budhathoki, R., B. Bruce, and Z. Nedovic-Budic. 200. Reconceptualizing the role of the user of spatial data infrastructure. Geojournal 72(3/4): 149-60.

Bussi, M. 2001. Géographie, démocratie, participation: Explication d'une distance, arguments pour un rapprochement. Géocarrefour 76(3): 265-72.

Carver, S., A. Evans, R. Kingston, and I. Turton. 2001. Public participation, GIS, and cyberdemocracy: Evaluating online spatial decision support systems. Environment and Planning B: Planning and Design 28(6): 907-21.

Cinderby, S. 2010. How to reach the "hard-to-reach": The development of participatory geographic information systems (P-GIS) for inclusive urban design in UK cities. Area 42(2): 239-51.

Cinnamon, J., and N. Schuurman. 2010. Injury surveillance in low-resource settings using geospatial and social Web technologies. International Journal of Health Geographics 9(25). Doi: 10.1186/1476-072X-9-25.

Coleman, D. J., Y. Georgiadou, and J. Labonte. 2009. Volunteered geographic information: The nature and motivation of produsers. International Journal of Spatial Data Infrastructures 4: 332-58.

Connor, D. M. 2007. A new ladder of citizen participation. National Civic Review 77(3): 249-57.

Craglia, M., M. F. Goodchild, A. Annoni, G. Camara, M. Gould, W. Kuhn, and E. Parsons. 2008. Next-generation digital earth. International Journal of Spatial Data Infrastructure Research 3: 146-67.

Craig, W., T. M. Harris, and D. Weiner, Eds. 2002. Community participation and geographic information systems. London: Taylor and Francis.

Crampton, J. W. 2009. Cartography: Maps 2.0. Progress in Human Geography 33(1): 91-100.

Crampton, J. W., M. Graham, A. Poorthuis, T. Shelton, M. Stephens, M. W. Wilson, and M. Zook. 2013. Beyond the geotag: Situating "big data" and leveraging the potential of the Geoweb. Cartography and Geographic Information Science 40(2): 130-9.

Creighton, J. L. 1983. Identifying publics/staff identification techniques. Fort Belvoir: The Institute for Water Resources.

DiNucci, D. 1999. Fragmented future. Print 53(4): 32.

Dragicevic, S., and S. Balram. 2004. A Web GIS collaborative framework to structure and manage distributed planning processes. Journal of Geographical Systems 6(2): 133-53.

Elwood, S. 2006. Negotiating knowledge production: The everyday inclusions, exclusions, and contradictions of participatory GIS research. The Professional Geographer 58(2): 197-208.

Elwood, S. 2009. Integrating participatory action research and GIS education: Negotiating methodologies, politics, and technologies. Journal of Geography in Higher Education 33(1): 51-65.

Flaxman, M. 2010. GeoDesign: Fundamental principles. Paper presented at the 2010 GeoDesign Summit, January 6 to 8, 2010, Redlands.

Gagnon, É., and A. Fortin. 2002. L'espace et le temps de l'engagement bénévole: Essai de definition. Nouvelles Pratiques Sociales 15(2): 66-76.

Gallis, M. 2010. GeoWeb 2.0. Paper presented at the 2010 GeoDesign Summit, January 6 to 8, 2010, Redlands.

Ghose, R. 2001. Use of information technology for community empowerment: Transforming geographic information systems into community information systems. Transactions in GIS 5(2): 141-63.

Ghose, R. 2007. Politics of scale and networks of association in public participation GIS. Environment and Planning A 39(8): 1,961-80.

Goodchild, M. F. 2005. What does Google Earth mean for the spatial sciences? Paper presented at the Biennial Conference of the Spatial Sciences Institute, September 12 to 16, 2005, Melbourne, Australia.

Goodchild, M. F. 2007a. Citizens as sensors: The world of volunteered geography. GeoJournal 69(4): 211-21.

Goodchild, M. F. 2007b. Citizens as sensors: Web 2.0 and the volunteering of geographic information. Geofocus 7: 8-10.

Goodchild, M. F. 2008. Assertion and authority: The science of user-generated geographic content (proceedings of the colloquium for Andrew U. Frank's 60th birthday). Paper presented at the Geoinfo 39, Vienna, Austria. 
Goodchild, M. F. 2010. Spatial by design. Paper presented at the 2010 GeoDesign Summit, January 6 to 8, 2010, Redlands.

Gordon-Murname, L. 2006. Social bookmarking, folksonomies, and Web 2.0 tools. Searcher: the Magazine for Database Professionals 14(6): 26-38.

Haklay, M. 2013. Neogeography and the delusion of democratization. Environment and Planning A 45(1): 55-69.

Han, S. S., and Z. Peng. 2003. Public participation GIS (PPGIS) for town council management in Singaport. Environment and Planning B: Planning and Design 30: 89-111.

Herring, C. 1994. An architecture of cyberspace: Spatialization of the Internet. Champaign: U.S. Department of Defense.

Jankowski, P., and T. Nyerges. 2001. Geographic information systems for group decision making. London: Taylor and Francis.

Jankowski, P., and T. Nyerges. 2003. Toward a framework for research on geographic information-supported participatory decision making. URISA Journal 15(APA I): 9-17.

Jankowski, P., T. Nyerges, S. Robischon, K. Ramsey, and D. Tuthill. 2006. Design considerations and evaluation of a collaborative, spatio-temporal decision support system. Transactions in GIS 10(3): 335-54.

Kingston, R., S. Carver, A. Evans, and I. Turton. 2000. Web-based public participation geographical information systems: An aid to local environmental decision making. Computers, Environment and Urban Systems 24(2): 109-25.

Kwan, M. P. 2002. Feminist visualization: Re-envisioning GIS as a method in feminist geographic research. Annals of the Association of American Geographers 92(4): 645-61.

Lévy, P. 1997. Collective intelligence: Mankind's emerging world in cyberspace. Cambridge: Perseus.

Maguire, D. J. 2007. GeoWeb 2.0 and volunteered GI. Paper presented at the Workshop presented on Volunteered Geographic Information, Santa Barbara. Http://www.ncgia.ucsb. edu/ projects/vgi/docs/position/Maguire_paper.pdf.

McCall, M. 2003. Seeking good governance in participatory GIS: A review of processes and governance dimensions in applying GIS to participatory spatial planning. Habitat International 27(4): 549-73.

Mericskay, B., and S. Roche. 2010. La néogéographie ou la cartographie à l'ère du Web 2.0. Géoinfo: chroniques du Québec géographie, dated July 2010. Retrieved from http://www. quebecgeographique.gouv.qc.ca/approfondir/bibliotheque/ geoinfo/geoinfo-juillet-2010.asp.

Miller, C. 2006. A beast in the field: The Google Maps mashup as GIS/2. Cartographica 41(3): 187-99.

Nyerges, T. 2005a. Public participation GIS support for transportation improvement decision making in the age of instant access. Paper presented at the Symposium on Societies and Cities in the Age of Instant Access, Salt Lake City.

Nyerges, T. 2005b. Scaling-up and a grand challenge for public participation GIS. Directions Magazine 2005-09-20.

O'Reilly, T. 2005. What is Web 2.0_-design patterns and business models for the next generation of software. San Francisco: O'Reilly.
Owens, S. 2000. "Engaging the public": Information and deliberation in environmental policy. Environment and Planning A 32(7): 1,141-48.

Pain, R., and S. Kindon. 2007. Participatory geographies. Environment and Planning A 39(12): 2.807-12.

Peng, Z. 1999. An assessment framework for the development of Internet GIS. Environment and Planning B: Planning and Design 26: 117-32.

Peng, Z. 2001. Internet GIS for public participation. Environment and Planning B: Planning and Design 28: 889-905.

Perkins, D. D., B. B. Brown, and R. B. Taylor. 1996. The ecology of empowerment: Participation in community organizations. Journal of Social Issues 52(1): 85-110.

Peterson, M. P. 2005. A decade of maps and the Internet. Proceedings of the 22nd International Cartographic Conference, July 9 to 16,2005 , A Coruña, Spain.

Pickles, J. 1997. Tool or science? GIS, technoscience, and the theoretical turn. Annals of the Association of American Geographers 87(2): 363-72.

Rambaldi, G. 2006. Gestion participative de l'information géographique et de la communication dans les pays en developpement. Electronic Journal on Information Systems in Developing Countries 25(1): 1-11.

Ramsey, K., and M. W. Wilson. 2006. Rethinking the "informed" participant: Precautions and recommendations for the design of online deliberation. In Davies, T., and B. Noveck. Eds., Online deliberation: Design, research, and practice. Stanford: CSLI.

Rinner, C., and M. Bird. 2009. Evaluating community engagement through argumentation maps — a public participation GIS case study. Environment and Planning B: Planning and Design 36(4): 588-601.

Rinner, C., C. Ke ler, and S. Andrulis. 2008. The use of Web 2.0 concepts to support deliberation in spatial decision making. Computers, Environment and Urban Systems 32(5): 386-95.

Rinner, C., J. Kumari, and S. Mavedati. 2011. A geospatial Web application to map observations and opinions in environmental planning. In Li, S., S. Dragicevic, and B. Veenendaal, Eds., Advances in WebGIS, mapping services, and applications. London: Taylor and Francis, pp. 277-91.

Robinson, P., and C. Gore,. 2005. Barriers to Canadian municipal response to climate change. Canadian Journal of Urban Research 14 (Summer 2005 Supplement): 102-20.

Rosenstone, S. J., and J. M. Hansen. 1993. Mobilization, participation, and democracy in America. New York: MacMillan.

Rowe, G., and L. J. Frewer. 2000. Public participation methods: A framework for evaluation. Science, Technology, and Human Values 25(1): 3-29.

Sani, A., and C. Rinner, 2011. A scalable GeoWeb tool for argumentation mapping. Geomatica 65(2): 145-56.

Scharl, A., and K. Tochtermann, Eds. 2007. The geospatial Web: How geobrowsers, social software and the Web 2.0 are shaping the network society. London: Springer. 
Schlossburg, M., and E. Shuford. 2005. Delineating "public" and "participation" in PPGIS. URISA Journal 16(2): 15-26.

Sieber, R. 2006. Public participation geographic information systems: A literature review and framework. Annals of the Association of American Geographers 96(3) 491-507.

Sieber, R. 2008. Participatory Geoweb: A research agenda. Proceedings of the Spatial Knowledge and Information Canada Conference (SKI-Canada), Volume 2, February 14 to 17, 2008, Fernie, BC, Canada.

Taylor, D. R. F., and S. Claquard. 2006. Cybercartography: Maps and mapping in the information era. Cartographica 41(1): $1-5$.

Tulloch, D. 2007. Many, many maps: Empowerment and online participatory mapping. First Monday 12(2).
Wang, W., and S. French. 2008. A multidimensional framework for facilitating wide participation and common understanding. Paper presented at the WebScience '08, Pittsburgh.

Ward, S., R. Gibson, and W. Lusoli. 2003. Online participation and mobilization in Britain: Hype, hope, and reality. Parliamentary Affairs 56(4): 652-68.

Wiedemann, P. M., and S. Femers. 1993. Public participation in waste management decision making: Analysis and management of conflicts. Journal of Hazardous Materials 33(3): 355-68.

Williams, G. 2004. Evaluating participatory development: Tyranny, power, and (re)politicisation. Third World Quarterly 25(3): 557-78. 